\title{
Dexamethasone enhances cell resistance to chemotherapy by increasing adhesion to extracellular matrix in human ovarian cancer cells
}

\author{
Yu-Xia Chen*, Yan Wang*, Chen-Chun Fu, Fei Diao, Liang-Nian Song ${ }^{1}$, \\ Zong-Bin Li, Rui Yang and Jian Lu
}

\author{
Department of Pathophysiology, the Second Military Medical University, 800 Xiangyin Road, Shanghai 200433, \\ People's Republic of China \\ ${ }^{1}$ Department of Medicine, Herbert Irving Comprehensive Cancer Center, Columbia University Medical Center, ICRC Room 207, \\ 1130 St Nicholas Avenue, New York, New York 10032, USA \\ (Correspondence should be addressed to J Lu; Email: lujian326@163.com)
}

${ }^{*}(\mathrm{Y}-\mathrm{X}$ Chen and $\mathrm{Y}$ Wang contributed equally to this work $)$

\begin{abstract}
Glucocorticoids (GCs) are widely used as co-medication in the therapy of solid malignant tumors to relieve some of the side effects of chemotherapeutic drugs. However, recent studies have shown that GCs could render cancer cells more resistant to cytotoxic drug-induced apoptosis, but the mechanism is largely unknown. In the present study, we found that the treatment of human ovarian cancer cell lines HO-8910 and SKOV3 with synthetic GCs dexamethasone (Dex) significantly increased their adhesion to extracellular matrix (ECM) and their resistance to apoptosis induced by cytotoxic drugs cisplatin and paclitaxel. Dex also increased the protein levels of adhesion molecules integrins $\beta 1, \alpha 4$, and $\alpha 5$ in $\mathrm{HO}-8910$ cells. The neutralizing antibody against integrin $\beta 1$ prevented Dex-induced adhesion and significantly abrogated the protective effect of Dex toward cytotoxic agents. We further found that transforming growth factor- $\beta 1$ (TGF- $\beta 1$ ) alone not only increased cell adhesion and cell survival of $\mathrm{HO}-8910$ cells in the presence of cisplatin, but also had synergistic pro-adhesion and pro-survival effects with Dex. Moreover, TGF- $\beta 1$ neutralizing antibody that could block TGF- $\beta 1$-induced cell adhesion and apoptosis resistance markedly abrogated the synergistic pro-adhesion and pro-survival effects of Dex and TGF- $\beta 1$. Finally, we further demonstrated that Dex could up-regulate the expression of TGF- $\beta$ receptor type II and enhance the responsiveness of cells to TGF- $\beta 1$. In conclusion, our results indicate that increased adhesion to ECM through the enhancement of integrin $\beta 1$ signaling and TGF- $\beta 1$ signaling plays an important role in chemoresistance induced by GCs in ovarian cancer cells.
\end{abstract}

Endocrine-Related Cancer (2010) 17 39-50

\section{Introduction}

Glucocorticoids (GCs) are being used in the treatment of childhood leukemia for several decades (Frei et al. 1965), and they have become one of the common drugs in almost all chemotherapy protocols for lymphoid malignancies due to their ability to induce apoptosis in the majority of hematological cells and efficiently kill lymphoid cells (Schmidt et al. 2004). Nowadays, GCs are also widely used as co-medication in cancer therapy of solid malignant tumors because of their effectiveness in the treatment of the malignant tumors or treatment-related edema, inflammation, pain, and electrolyte imbalance, as well as due to their ability to stimulate appetite, to prevent nausea, emesis, and toxic reactions caused by cytotoxic treatment (Rutz 2002, Rutz \& Herr 2004). GCs are also given before, during, and after chemotherapy of solid malignant tumors to reduce acute toxicity, particularly hyperemesis, and to protect normal tissue, e.g. bone marrow progenitor cells, of cancer patients against the long-term effects of genotoxic drugs (Kriegler et al. 1994). 
While GCs strongly induce apoptosis in the cells of the hematological lineage, they also support survival in several nonhematological tissues such as mammary gland, liver, lung, glioma, and subcutaneous adipocytes (Moran et al. 2000, Schorr \& Furth 2000, Mikosz et al. 2001, Zhang et al. 2001, Bailly-Maitre et al. 2002, Webster et al. 2002). More recent data indicate that GCs can inhibit apoptosis induced by chemotherapy not only in established cancer cell lines and tumor xenografts, but also in the freshly isolated cells from surgical resections from tumors of various origins, including ovary, breast, prostate, pancreas, liver, colon, brain, cervix, bone, skin, and nervous system (Herr et al. 2003, Sui et al. 2006, Zhang et al. 2006a,b,c,d,e). In addition, the anti-chemotherapeutic effect of GCs can be seen in several anticancer drugs including cisplatin (Wolff et al. 1996, Gassler et al. 2005, Zhang et al. 2006a,b,d, 2007), paclitaxel (Wu et al. 2004, 2005, Sui et al. 2006), 5-fluorouracil (Zhang et al. 2006a, 2007), adriamycin (Weller et al. 1997), actinomycin D (Wolff et al. 1996), doxorubicin (Wu et al. 2004), and gemcitabine (Gassler et al. 2005, Zhang et al. 2007). The GC-induced pro-survival effects should be of important clinical relevance when they interfere with the effect of chemotherapeutics. Recent studies suggest that GC-conferred cellular resistance to cancer therapy may occur through multiple mechanisms, for example, by enhancing DNA repair capacity, suppressing host anti-tumor immune responses, and blocking apoptosis (Rutz 2002, Herr et al. 2003, Rutz \& Herr 2004). Some dexamethasone (Dex)-induced proteins, such as the inhibitors of apoptosis (cIAP-2, X-IAP, Bcl-XL, and Bcl-2), mitogen-activated protein kinase phosphatase-1, as well as GC-induced serum, and GC-inducible kinase-1 (SGK-1) may contribute to the prevention of chemotherapy-induced apoptosis by GCs (Webster et al. 2002, Herr et al. 2003, Wu et al. 2004, 2005, Runnebaum \& Brüning 2005, Herr et al. 2007). However, the molecular mechanisms underlying the anti-apoptotic effect of GCs in epithelial cells are still largely unknown.

In our previous work, we found that Dex could dramatically prolong the detachment time of the cells digested with trypsin in human ovarian cancer cell line HO-8910, suggesting that Dex may be able to increase the cell adhesion ability to extracellular matrix (ECM). Since cell adhesion to ECM is pivotal for the survival and growth of most of the solid cancer cells derived from epithelium (Rozzo et al. 1997, Pinkse et al. 2004), we hypothesized that the increase in cell resistance to cytotoxic therapyinduced apoptosis by Dex may be due to its promotion effect in cell adhesion to ECM. Therefore, in the present study, we investigated the effect of Dex on cell adhesion to ECM of two human ovarian cancer cell lines, HO-8910 and SKOV3, and examined the relationship between Dex's effect of enhancing adhesion and Dex-induced cell resistance to chemotherapeutic agents. We further explored the mechanism of Dex's action and mainly focused on the adhesion molecular integrin $\beta 1$ subfamily, as well as on the transforming growth factor- $\beta 1$ (TGF- $\beta 1$ ) signaling. Our results provide new evidence that Dex's role in pro-adhesion through the enhancement of integrin $\beta 1$ signaling and TGF- $\beta 1$ signaling is one of the basic mechanisms responsible for Dex-induced apoptotic resistance against chemotherapy in ovarian cancer cells.

\section{Materials and methods}

\section{Cell culture}

Human ovarian cancer cell line HO-8910 was described previously (Chen et al. 2006). Human ovarian cancer cell line SKOV3 was cultured in RPMI-1640 (Invitrogen) supplemented with $10 \%$ fetal bovine serum, $100 \mathrm{U} / \mathrm{ml}$ penicillin, and $100 \mu \mathrm{g} / \mathrm{ml}$ streptomycin (Huashun Technology, Inc., Shanghai, China) at $5 \% \mathrm{CO}_{2}$ and at $37{ }^{\circ} \mathrm{C}$.

\section{Semi-quantitative reverse transcription-PCR}

Total RNA was extracted with the TRIzol reagent (Invitrogen). After reverse transcription (RT), the cDNA products were amplified by PCR at an annealing temperature of $58{ }^{\circ} \mathrm{C}$ (integrin $\beta 1$ ) or $55^{\circ} \mathrm{C}$ (TGF- $\beta$ receptor type II (T $\beta \mathrm{R}-\mathrm{II})$, glyceraldehyde-3-phosphate dehydrogenase (GAPDH)). The amplifying cycles and templates were 24 cycles and $75 \mathrm{ng}$ cDNA for integrin $\beta 1,24$ cycles and $40 \mathrm{ng}$ cDNA for T $\beta \mathrm{R}-\mathrm{II}$, and 20 cycles and $20 \mathrm{ng}$ cDNA for GAPDH according to the results of optimization. The primers were sense $5^{\prime}$-GCACGTTCAGAAGTCGGTT- $3^{\prime}$ and antisense 5'-AGATATGGCAACTCCCAGTGGT-3' for T $\beta$ R-II (467 bp; Li et al. 2006), sense 5'-ACACGTCTCTCTCTGTCG- $3^{\prime}$ and antisense 5'-CAGTTGTTACGGCACTCT- $3^{\prime}$ for integrin $\beta 1$ (157 bp; Kappert et al. 2000), and sense $5^{\prime}$-TTCATTGACCTCAACTACATG- $3^{\prime}$ and antisense $5^{\prime}$-GTGGCAGTGATGGCATGGAC-3' for GAPDH (443 bp). PCR products were separated on $2 \%$ agarose gels and visualized by ethidium bromide staining. 


\section{Western blotting}

Total cell lysates were prepared with $1 \times$ SDS lysis buffer containing $0.1 \mathrm{mM} \quad \beta$-mercaptoethanol, and $2 \mu \mathrm{g} / \mathrm{ml}$ of each of the protease inhibitors leupeptin, aprotinin, and pepstatin. After electrophoresis, the protein was transferred to a nitrocellulose membrane, blocked with $5 \%$ nonfat milk, and probed overnight with primary antibodies against integrin $\beta 1$ (Upstate, Lake Placid, NY, USA, 1/500), integrins $\alpha 4$ and $\alpha 5$ (Chemicon, Temecula, CA, USA, 1/500), T $\beta R$-II (Santa Cruz Biotechnology, Santa Cruz, CA, USA, 1/500), cleaved caspase-3 (Asp175) (Cell Signaling, Boston, MA, USA, 1/500), and $\beta$-actin (Sigma, $1 / 10000)$. The blots were then washed, exposed to HRP-conjugated secondary antibodies (Rockland Immunochemicals, Gilbertsville, PA, USA, 1/5000) for $2 \mathrm{~h}$, and finally detected by ECL chemiluminescence (Pierce, Rockford, IL, USA).

\section{Transient transfection and luciferase assay}

Twenty-four hours before transfection, HO-8910 cells were plated in triplicate into a 24 -well plate at a density of $5 \times 10^{4}$ cells/well. Cells were transiently transfected with $1 \mu \mathrm{g} /$ well of p3TP-Luc-driven luciferase reporter plasmid (kindly provided by Dr J Massagué) using Lipofectamine plus transfection reagent (Invitrogen Life Technologies). In order to normalize the transfection efficiency, pRL-TK-Renilla-luc (30 ng/well, Promega) was co-transfected into the cells. Cells were grown for $12 \mathrm{~h}$ and then treated with $10^{-7} \mathrm{M} \mathrm{Dex}$ (Sigma-Aldrich Chemicals) and/or $10 \mathrm{ng} / \mathrm{ml}$ TGF- $\beta 1$ (Peprotech, Rocky Hill, NJ, USA) for $24 \mathrm{~h}$. The luciferase activities were determined using the dual luciferase assay system. Values were normalized by renilla luciferase, and are presented as fold induction over control.

\section{Analysis of viability}

Cells were seeded at $2 \times 10^{3}$ cells/well in 96-well culture plates in triplicate, and cultured in RPMI-1640 containing 5\% charcoal-dextran-stripped CBS. Cisplatin (Sigma-Aldrich Chemicals), paclitaxel (a gift from Prof. Zhu Minghua, Department of Pathology, Changhai Hospital, Second Military Medical University), and/or Dex were added and refreshed for every other $24 \mathrm{~h}$. For the blockade assay, $10-20 \mu \mathrm{g} / \mathrm{ml}$ integrin $\beta 1$ antibody, $10 \mu \mathrm{g} / \mathrm{ml}$ TGF- $\beta 1$ antibody, or control IgG was also added to the medium. At the indicated time, the viable cells were determined by 3-(4,5-dimethylthiazol-2-yl)-2,5-diphenyltetrazolium bromide (MTT) assay as described before (Chen et al. 2006).

\section{Measurement of apoptosis}

Cells were cultured in appropriate media containing $5 \%$ CBS with each agent for the indicated time. Cells were trypsinized and stained with FITC-conjugated annexin $\mathrm{V}$ and propidium iodide (BD Biosciences, Heidelberg, Germany) according to the manufacturer's instructions. The apoptotic cells were analyzed by flow cytometric analysis.

\section{Cell adhesion assay}

Cell adhesion ability to ECM was determined by cell adhesion assay (Chen et al. 2004). Cells were incubated in the medium containing the agents for the indicated time and were then digested and counted. Cells, $8 \times 10^{4}$, were seeded into 96 -well plates precoated with $10 \mu \mathrm{g} / \mathrm{ml}$ fibronectin (FN; Calbiochem, Darmstadt, Germany) and incubated at $37^{\circ} \mathrm{C}$ for $1 \mathrm{~h}$. The plates were gently washed thrice with PBS to remove the unattached cells. The remaining cells in the 96-well plates were determined by MTT assay.

For the blockade experiment, the 96-well plates were precoated with $10 \mu \mathrm{g} / \mathrm{ml} \mathrm{FN}$ for $1 \mathrm{~h}$, followed by $1 \%$ BSA for $45 \mathrm{~min}$ at $37^{\circ} \mathrm{C}$. Resuspended cells, $2 \times 10^{4}$, were incubated with $10-20 \mu \mathrm{g} / \mathrm{ml}$ integrin $\beta 1$ antibody, $10 \mu \mathrm{g} / \mathrm{ml}$ TGF- $\beta 1$ antibody, or control IgG for another $45 \mathrm{~min}$ at $37^{\circ} \mathrm{C}$ before seeding into wells to detect the cell adhesion ability with the same procedure as described above.

\section{Statistical analysis}

Data are expressed as mean \pm s.D. of at least three determinations. Statistical significance between experimental groups was analyzed by ANOVA, and the significance level was set at $P<0.05$.

\section{Results}

\section{Dex increases cell viability by the inhibition of chemotherapeutic drug-induced apoptosis in ovarian cancer cells HO-8910 and SKOV3}

We first investigated the effects of cisplatin or paclitaxel alone or plus Dex on the survival of HO8910 cells. As shown in Fig. 1A, cisplatin could significantly decrease the survival cell number in a dose-dependent manner. Co-treatment of cells with Dex and different doses of cisplatin significantly increased the survival cell number. Dex, $10^{-7} \mathrm{M}$, increased the survival cell number by $53.8 \%(P<0.01)$ in the presence of $2 \mu \mathrm{g} / \mathrm{ml}$ cisplatin, a dose commonly used in the clinic. A similar protective effect of Dex was also seen when cells were treated with paclitaxel, 

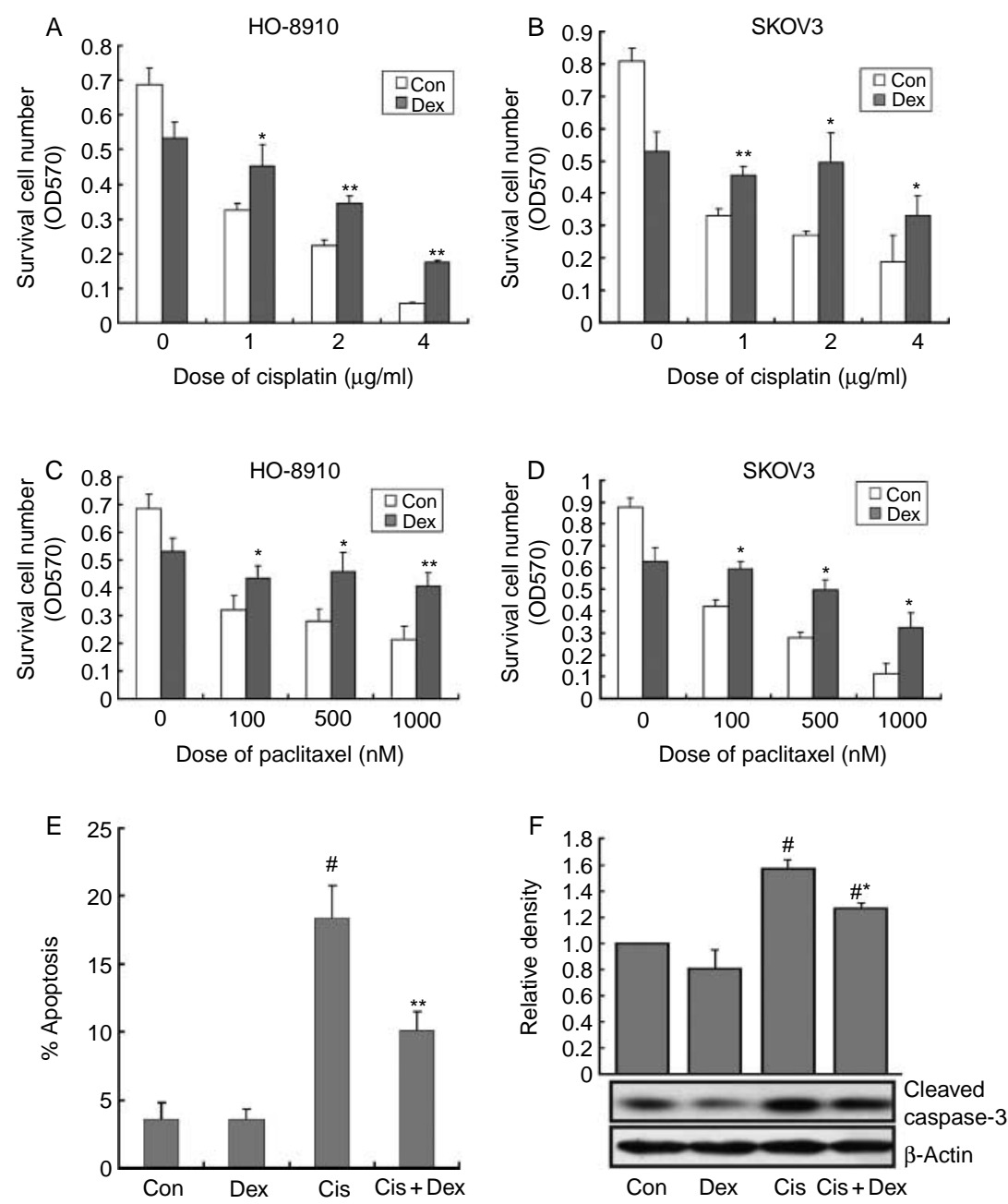

Figure 1 Dex protects cell survival in response to cytotoxic drugs in human ovarian cancer cells HO-8910 and SKOV3. (A-D) The detection of cell survival by MTT assay. HO-8910 ( $A$ and $C$ ) and SKOV3 (B and D) cells were cultured in a medium containing ethanol or various doses of cisplatin $(A$ and $B)$ or paclitaxel $(C$ and $D)$ as indicated in the absence or presence of $10^{-7} M$ Dex for 4 days, and then the viability was monitored. Values plotted are mean \pm S.E.M. ${ }^{\star} P<0.05,{ }^{\star \star} P<0.01$ versus corresponding dose of cytotoxic drugs. ( $E$ and $F$ ) Dex protects cell apoptosis against cisplatin in HO-8910 cells. HO-8910 cells were cultured in a medium containing ethanol or $2 \mu \mathrm{g} / \mathrm{ml}$ cisplatin in the absence or presence of $10^{-7} \mathrm{M}$ Dex for $48 \mathrm{~h}$. Apoptosis was analyzed by staining the cells with annexinFITC and by FACS analysis (E). The expression of cleaved caspase-3 was determined by western blotting (F). Relative densitometric units of cleaved caspase-3/ $\beta$-actin are shown in the upper panel, with the density of the control bands set at 1.0 . Experiments were performed thrice with similar results. Values plotted are mean \pm S.E.M. ${ }^{\#} P<0.05$ versus control, ${ }^{\star} P<0.05$, ${ }^{\star *} P<0.01$ versus cisplatin.

another chemotherapeutic drug (Fig. 1C). These findings were confirmed in SKOV3, a different human ovarian cancer cell line (Fig. 1B and D).

Since $10^{-7} \mathrm{M}$ Dex alone led to a slight inhibition of cell growth by about $20 \%$ (Fig. 1A), the increase in survival cell number when cells were co-treated with Dex and cisplatin or paclitaxel was not due to the acceleration of cell growth, but most probably was due to the Dex-induced attenuation of cell apoptosis caused by cytotoxic drugs. To test this probability, we further examined the change in apoptosis of HO-8910 cells treated with cisplatin $(2 \mu \mathrm{g} / \mathrm{ml})$ or Dex $\left(10^{-7} \mathrm{M}\right)$ alone or with a combination of Dex and cisplatin for $48 \mathrm{~h}$ by flow cytometry. As shown in Fig. 1E, cisplatin resulted in remarkable cell apoptosis with $18.38 \%(P<0.05)$. However, co-treatment of cells with Dex and cisplatin significantly diminished the apoptosis of cells to $10.1 \%(P<0.01)$. Moreover, Dex could also inhibit the activation of caspase- 3 protein by cisplatin in HO-8910 cells (Fig. 1F). These results indicate that Dex increases cell viability by protecting the cells against apoptosis induced by chemotherapeutic drugs. 
Dex increases cell adhesion ability of ovarian cancer cells in the absence or presence of cisplatin

Our preliminary studies found that HO-8910 cells treated with Dex were more resistant to trypsin digestion than cells treated with a vehicle control. The detachment time of the cells treated with or without $10^{-7} \mathrm{M}$ Dex for $24 \mathrm{~h}$ followed by digestion with $0.25 \%$ trypsin was $16 \pm 3.5$ and $4 \pm 0.5 \mathrm{~min}$ respectively. This phenomenon was also observed in SKOV3 cells, suggesting that the cell adhesion to ECM may be strengthened by Dex. We further investigated the effect of Dex on cell adhesion ability. As shown in Fig. 2A and B, Dex could significantly increase the cell adhesion ability to FN-coated culture plates in a timeand dose-dependent manner in both HO-8910 and SKOV3 cells. In addition to the increased cell adhesion ability, Dex treatment also induced a fibroblast-like change in cell morphology (data not shown).

Based on the above-mentioned data, we proposed that Dex-enhanced adhesion to ECM may be involved in its protecting the cells from apoptosis induced by chemotherapeutic drugs. To test this hypothesis, we investigated the effect of cisplatin on cell adhesion in the absence or presence of Dex. As shown in Fig. 2C, in the absence of Dex, the treatment of cells with cisplatin for $24 \mathrm{~h}$ dramatically decreased the adhesive cell number by $51 \%(P<0.05)$ as compared with that of the control. However, when cells were treated with both cisplatin and increasing concentrations of Dex, the adhesive cell number gradually increased. There was a twofold increase in the adhesive cells at $10^{-7} \mathrm{M}$ Dex compared to the cells treated with cisplatin alone.

\section{Dex up-regulates protein expressions of integrins $\alpha 4 \beta 1$ and $\alpha 5 \beta 1$ in $\mathrm{HO}-8910$ cells}

As one of the receptors of ECM proteins, adhesion molecular integrin $\beta 1$ subfamily plays a crucial role in regulating cell adhesion to ECM (Hynes 1992). All members of integrin $\beta 1$ subfamily are heterodimers formed by one common integrin $\beta 1$ subunit and different kinds of $\alpha$ subunits (Hynes 1992). We investigated the effect of Dex on the expression of integrin $\beta 1$ as well as on the two kinds of $\alpha$ subunit, $\alpha 4$ and $\alpha 5$, which are the primary receptors of FN in HO-8910 cells. As shown in Fig. 3, though Dex could not change the expression of integrin $\beta 1$ at the mRNA level (data not shown), it could induce the expression of integrins $\beta 1, \alpha 4$, and $\alpha 5$ at the protein levels in a time- and dose-dependent manner.
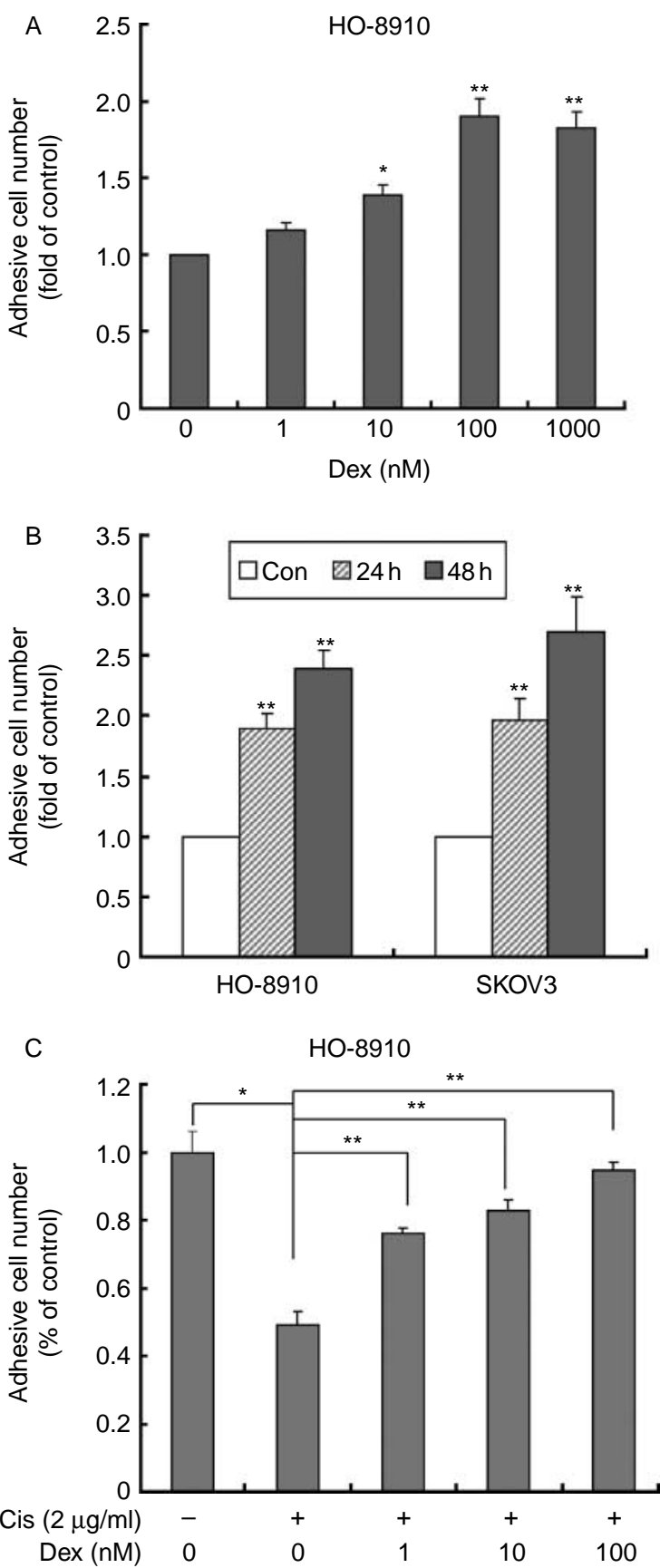

Figure 2 Dex enhances cell attachment to fibronectin and antagonizes the impairment of cisplatin on cell adhesion. Cells were pretreated with $0-1 \mu \mathrm{M}$ Dex for $24 \mathrm{~h}(\mathrm{~A})$ or with $10^{-7} \mathrm{M}$ Dex for 0-48 $\mathrm{h}(\mathrm{B})$, or treated with ethanol, $2 \mu \mathrm{g} / \mathrm{ml}$ cisplatin, or $2 \mu \mathrm{g} / \mathrm{ml}$ cisplatin combined with $1-10^{-7} \mathrm{M}$ Dex for $24 \mathrm{~h}(\mathrm{C})$. Cells, $8 \times 10^{4}$, were seeded into a 96 -well plate coated with $10 \mu \mathrm{g} / \mathrm{ml}$ fibronectin. Sixty minutes later, cells were washed thrice with PBS, and the number of the remaining cells that were attached was determined by MTT assay. Data are summarized from three independent sets of experiments. ${ }^{\star} P<0.05$ and ${ }^{\star \star} P<0.01$ versus control in $\mathrm{A}$ and $\mathrm{B} .{ }^{*} P<0.05,{ }^{* \star} P<0.01$ in $\mathrm{C}$. 


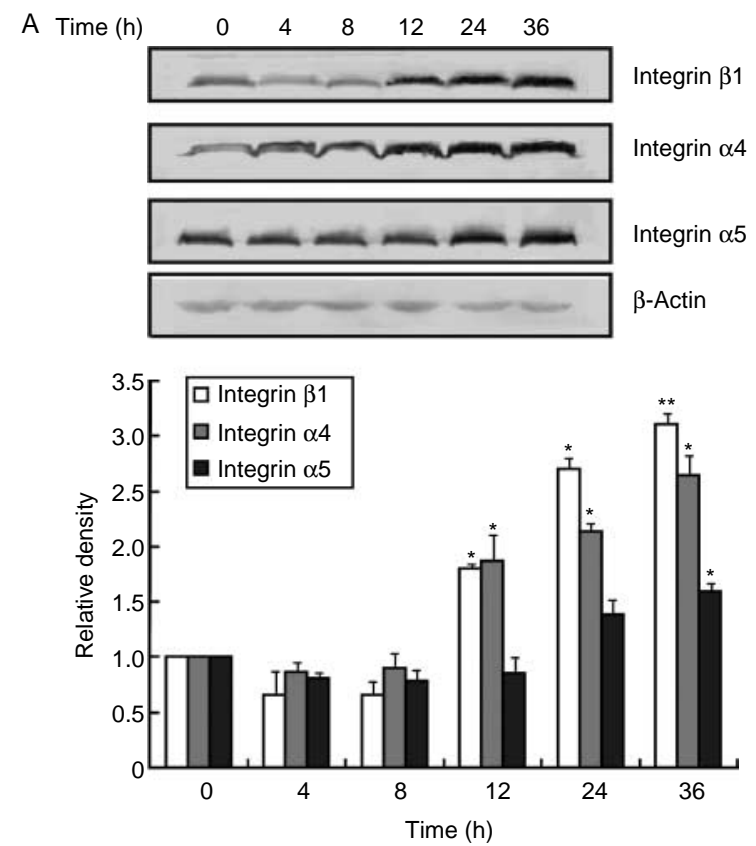

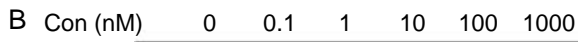
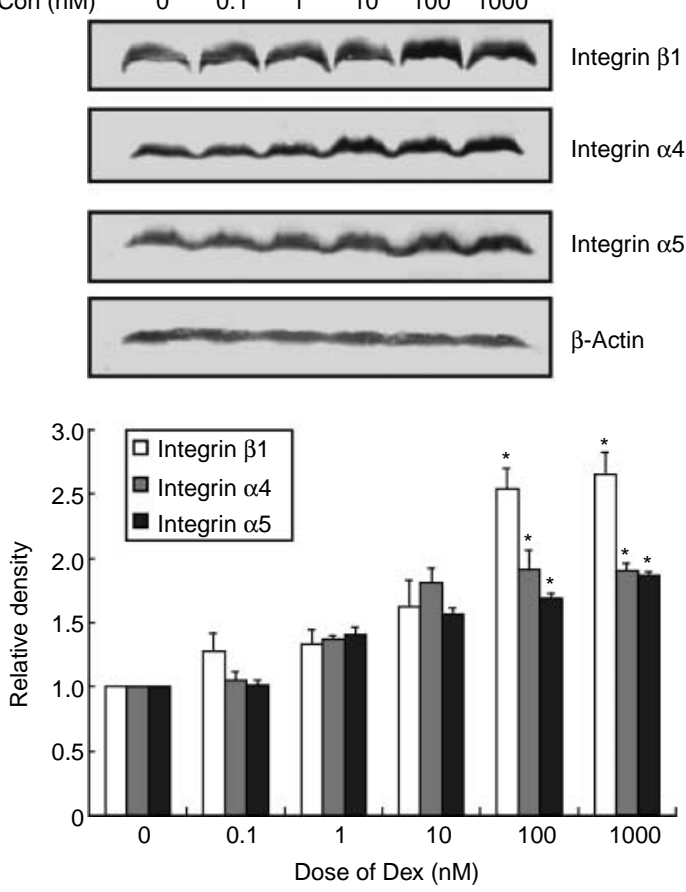

Figure 3 Dex induces the expressions of integrin $\beta 1, \alpha 4$, and $\alpha 5$ proteins in $\mathrm{HO}-8910$ cells. $\mathrm{HO}-8910$ cells were maintained in RPMI-1640 medium containing 5\% DCC-CBS for $24 \mathrm{~h}$ and then treated with $10^{-7} \mathrm{M}$ Dex for different time intervals $(A)$ or with different concentrations of Dex for $24 \mathrm{~h}(\mathrm{~B})$. Cells were then harvested for the detection of integrins $\beta 1, \alpha 4$, and $\alpha 5$ by western blotting. $\beta$-Actin was also detected for loading control. Relative densitometric units of integrin/ $\beta$-actin for time intervals and different concentrations are shown in the lower panel, with the density of the control bands set at 1.0. The blots represent one of the three independent experiments. ${ }^{*} P<0.05$, ${ }^{\star \star} P<0.01$ versus the control of the corresponding integrin subunits.

\section{Blocking of integrin $\beta 1$-mediated cell adhesion attenuates the protective effect of Dex on chemotherapeutic drug-induced apoptosis in HO-8910 cells}

In an effort to elucidate the role of Dex-induced expression of integrin $\beta 1$ in the protection of cells against chemotherapeutic agents, we further examined the influence of the integrin $\beta 1$-blocking antibody on the cell adhesion and cell survival. As shown in Fig. 4A, preincubation of the cells with integrin $\beta 1$-blocking antibody significantly blocked Dexinduced cell adhesion in a dose-dependent manner. As compared with Dex plus IgG group, addition of 10 and $20 \mu \mathrm{g} / \mathrm{ml}$ integrin $\beta 1$-blocking antibody reduced the number of cells attached by $25 \%(P<0.05)$ and $67.3 \%(P<0.01)$ respectively. Meanwhile, the cell survival protective effect of Dex was also decreased when the cells were treated with Dex combined with integrin $\beta 1$-blocking antibody. As shown in Fig. 4B, $20 \mu \mathrm{g} / \mathrm{ml}$ integrin $\beta 1$-blocking antibody could reduce the protective effect of Dex from cisplatin by $61.5 \%$ $(P<0.05)$. A similar but stronger reduction in the protective effect of Dex could be seen when paclitaxel was used in the experiments (Fig. 4C). These results indicate that the enhancement of cell adhesion to ECM, which is mainly mediated by integrin $\beta 1$ subfamily, plays an important role in GCs protecting cells against chemotherapeutic agents in HO-8910 cells.

\section{Dex and TGF- $\beta 1$ have a synergistic effect on enhancing cell adhesion and resistance to cisplatin in HO-8910 cells}

TGF- $\beta 1$ is the most important growth factor that facilitates cell adhesion to ECM by increasing matrix production and accumulation, as well as by enhancing the expression of cell adhesion molecules (Dawes et al. 2007). Considering that ovarian epithelial cells can secrete TGF- $\beta 1$ (Peng 2003), we therefore tested whether TGF- $\beta 1$-signaling pathway is involved in Dex's role in pro-adhesion and pro-survival.

As shown in Fig. 5A, the adhesion ability of cells treated with $10^{-7} \mathrm{M}$ Dex, $10 \mathrm{ng} / \mathrm{ml}$ TGF- $\beta 1$ alone, and both the agents for $24 \mathrm{~h}$ was 1.89 -fold $(P<0.01)$, 1.4-fold $(P<0.05)$, and 2.64-fold $(P<0.01)$ respectively compared to that of the control cells, indicating that TGF- $\beta 1$ not only increased adhesion of HO-8910 cells alone, but also had a synergistic pro-adhesion effect with Dex. Moreover, $10 \mu \mathrm{g} / \mathrm{ml}$ TGF- $\beta 1$ neutralizing antibody that could significantly block the pro-adhesion effect of TGF- $\beta 1$ markedly inhibited the synergistic effect of Dex and TGF- $\beta 1$ on cell adhesion. A similar synergistic pro-survival effect was 
also observed when cells were co-treated with Dex and TGF- $\beta 1$ in the presence of cisplatin. And such a synergistic effect was also markedly abrogated by TGF- $\beta$ 1-neutralizing antibody (Fig. 5B). These results indicate that TGF- $\beta 1$-signaling pathway is involved in Dex-induced cell adhesion to ECM as well as in the cell resistance to cisplatin in HO-8910 cells.
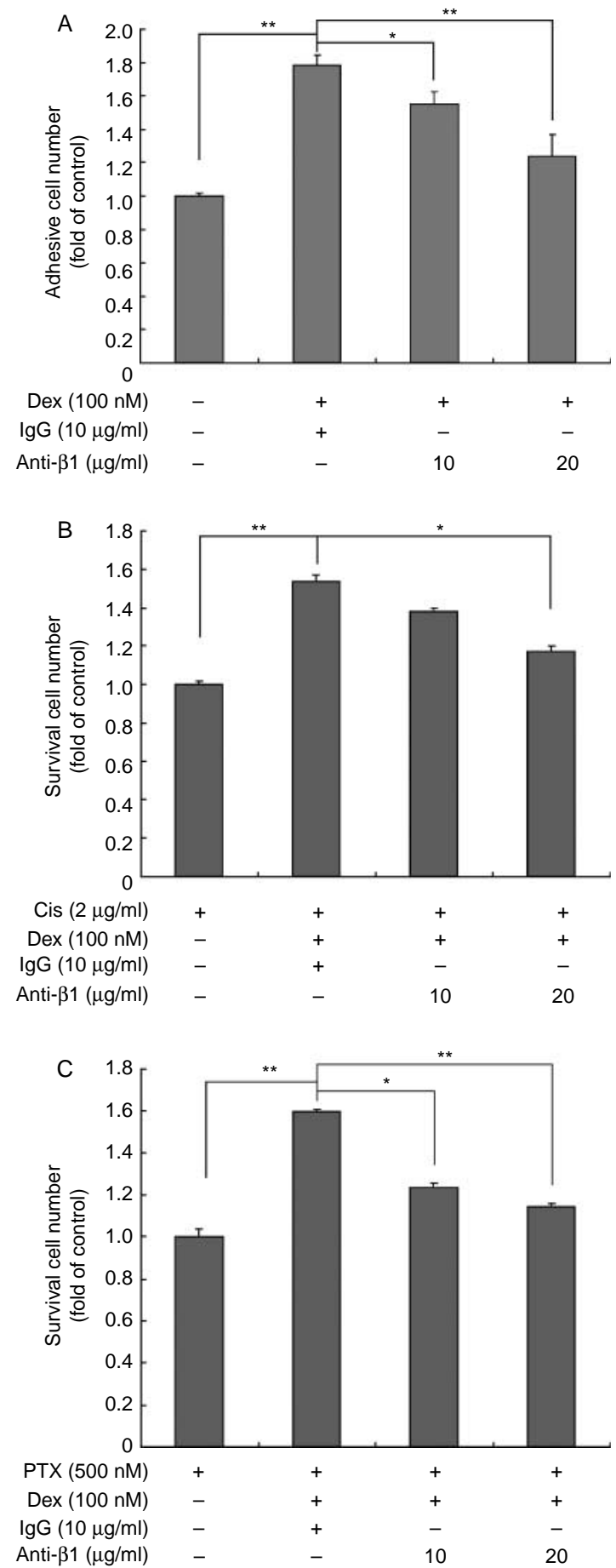

\section{Dex enhances the responsiveness of $\mathrm{HO}-8910$ cells to TGF- $\beta 1$ by increasing the expression of T $\beta R$-II}

The synergistic effect of Dex and TGF- $\beta 1$ on cell adhesion as well as on the cell resistance to cisplatin in HO-8910 cells suggests that there is a positive crosstalk between GC- and TGF- $\beta 1$-signaling pathways. Therefore, we examined the effect of Dex on the expression of TGF- $\beta 1$ and its two types of receptors (T $\beta$ R-I and $\mathrm{T} \beta \mathrm{R}-\mathrm{II})$. The results demonstrated that the expressions of TGF- $\beta 1$ and T $\beta R-I$ remain unaffected (data not shown), but T $\beta$ R-II expression in HO-8910 cells was significantly up-regulated by $10^{-7} \mathrm{M}$ Dex at both mRNA and protein levels (Fig. 5C).

It is well known that the binding of TGF- $\beta 1$ to constitutively active T $\beta$ R-II leads to the recruitment and interaction of T $\beta R$-I, which phosphorylates downstream Smad proteins that activate target genes in the nucleus. We then examined the response of cells to TGF- $\beta 1$ signaling by transient transfection of cells with p3TP-luc, a TGF- $\beta 1$-responsive reporter gene. As shown in Fig. 5D, TGF- $\beta 1$, Dex, and TGF- $\beta 1$ plus Dex induced a 2 -fold $(P<0.01), 1.5$-fold $(P<0.05)$, and 2.8 -fold $(P<0.01)$ increase in luciferase activity respectively. These results indicate that Dex may enhance the responsiveness of cells to TGF- $\beta 1$ by up-regulating the expression of T $\beta R$-II.

\section{Discussion}

Recently, more and more data from preclinical studies, and to some extent from clinical studies, have strongly recommended a GC-conferred resistance to cancer therapy in the majority of malignant solid tumors - irrespective of tumor origin and the nature of specific anticancer drugs (Wolff et al. 1996, Weller et al. 1997, Webster et al. 2002, Herr et al. 2003, Wu et al. 2004, 2005, Gassler et al. 2005, Runnebaum \& Brüning 2005, Sui et al. 2006, Zhang et al. 2006a,b,c,d,e, 2007). In this study, we have demonstrated that Dex could protect human ovarian

Figure 4 Dex-enhanced cell attachment and cell survival are partially reversed by integrin $\beta 1$-blocking antibody. (A) Cells were cultured in a medium in the absence or presence of $10^{-7} \mathrm{M}$ Dex for $24 \mathrm{~h}$ and were digested and counted. Cells, $2 \times 10^{4}$, were incubated with $\mathrm{lgG}, 10 \mu \mathrm{g} / \mathrm{ml}$, or $20 \mu \mathrm{g} / \mathrm{ml}$ integrin $\beta 1$-blocking antibody for $45 \mathrm{~min}$, and then seeded into a 96-well plate coated with $10 \mu \mathrm{g} / \mathrm{ml} \mathrm{FN}$. Sixty minutes later, the cell adhesion ability was assayed. (B and C) Cells, $2 \times 10^{3}$, were cultured in a medium containing chemotherapeutic drugs, and chemotherapeutic drugs plus $10^{-7} \mathrm{M}$ Dex, combined with either integrin $\beta 1$-blocking antibody or IgG for 4 days, and cell survival was detected by MTT assay. Data are representative of three independent sets of experiments. ${ }^{\star} P<0.05$, ${ }^{\star \star} P<0.01$. 
A

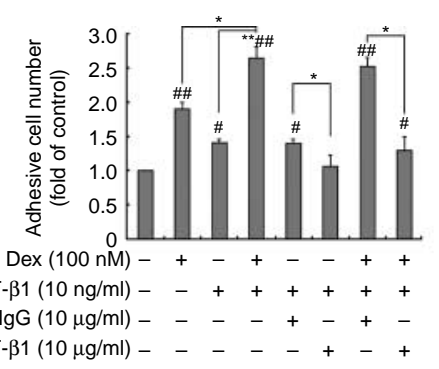

B

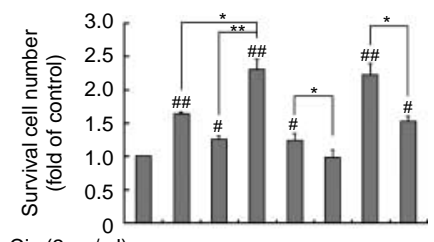

Cis $(2 \mu \mathrm{g} / \mathrm{ml})++++++++$

$\operatorname{Dex}(100 \mathrm{nM})-+-+--++$

TGF- $\beta 1(10 \mathrm{ng} / \mathrm{ml})--++++++$

$\operatorname{lgG}(10 \mu \mathrm{g} / \mathrm{ml})-[--\quad+\quad+\quad+-$ Anti-TGF- $\beta 1(10 \mu \mathrm{g} / \mathrm{ml})$
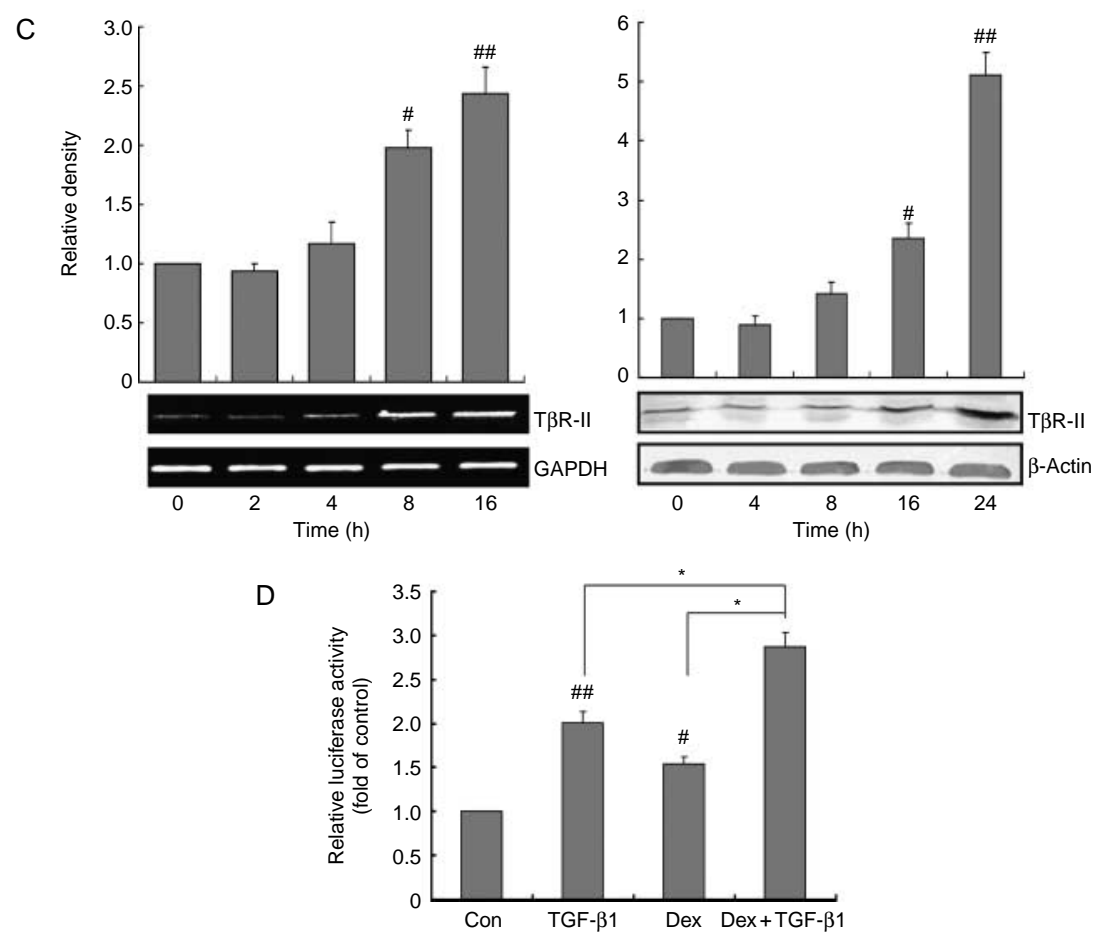

Figure 5 Dex enhances cell adhesion and survival responses to TGF- $\beta 1$ in HO-8910 cells. (A) Dex enhances cell adhesion ability induced by TGF- $\beta 1$. HO-8910 cells were treated with the indicated agents for $24 \mathrm{~h}$, and the cell adhesion ability was assayed. (B) Dex enhances TGF- $\beta 1$-induced cell apoptosis resistance to cisplatin. Cells were incubated with the indicated agents for 4 days, and the survival cell number was determined with MTT assay. (C) Dex increases the expression of TRR-II mRNA and protein in HO-8910 cells. Cells were treated with $10^{-7} \mathrm{M}$ Dex for different times, and T $\beta$ R-II mRNA and protein levels were determined by semi-quantitative RT-PCR and western blotting respectively. Relative densitometric units of T $\beta$ R-II/GAPDH and T $\beta$ R-II/ $\beta$-actin are shown in the upper panel, with the density of the control bands set at 1.0. The blots represent one of the three independent experiments. (D) Dex enhances the luciferase activity induced by TGF- $\beta 1$. Cells were transfected with the reporter plasmid P3TP-Luc, and were then incubated with agents as indicated. Sixteen hours later, cells were harvested and assayed for luciferase activity. All the results shown above are representative of three independent experiments. ${ }^{\#} P<0.05$, ${ }^{\# \#} P<0.01$ versus control (or cisplatin), ${ }^{\star} P<0.05$.

cancer cell lines HO-8910 and SKOV3 from apoptosis induced by chemotherapeutic drugs, including cisplatin and paclitaxel, as well as adriamycin and actinomycin D (data not shown).

These findings indicate that the use of GCs as co-medication in the therapy of ovarian carcinomas and other solid tumors may result in the desensitization to chemotherapy, ultimately leading to faster tumor growth. Therefore, GCs should be administered carefully in routine chemotherapy in cancer patients.
The protection of normal tissue by GCs may be good for patients, but the protection of cancer cells may impair the effect of chemotherapy. Thus, it is understandable that the appeal for reevaluating the administration of GCs in the management of solid cancer patients has emerged recently. After performing an overall statistical analysis of a large screening study, Zhang et al. (2007) also suggested the replacement of GCs by nonsteroidal anti-emetic agents, which do not induce therapy resistance. 
In addition to chemotherapy resistance, we also noticed that Dex alone led to an inhibition of cell growth in HO-8910 and SKOV3. Similar results were also reported in several other solid tumor cells such as glioblastoma cells and osteosarcoma cells (Mattern et al. 2007). The effects of GCs may reflect their important role in maintaining the homeostasis of cell number. They inhibit the proliferation of cells under physiological conditions; however, they enhance cell survival under the pressure of cytotoxic drugs and other harmful stimuli. Moreover, it is known that cell cycle arrest may reduce the sensitivity of cells to the chemotherapeutic drugs. So, Dex-induced cell growth inhibition and cell cycle arrest in G1 may also be one of the mechanisms of its anti-apoptotic effect on cancer therapy. Mattern et al. (2007) held a similar opinion that the inhibition of cell growth by inducing cell cycle arrest may be crucially involved in switching the balance of several interacting pathways to survival upon treatment with GCs.

For anchorage-dependent monolayer culture, attachment of cells to ECM is one of the prerequisites for cell survival, growth, and differentiation. As reported, Dex increased cell adhesion ability in lung fibroblasts (Brenner et al. 2001) and lens epithelial cells (Sawhney 2002), but decreased it in amnion epithelial cells (Guller et al. 1995a) and placental cells (Guller et al. 1995b), indicating that Dex plays a role in regulating cell adhesion to ECM in a cell-specific manner. Our study adds new data that Dex significantly promotes the adhesion of human ovarian cancer cells HO-8910 and SKOV3 to ECM, and demonstrates for the first time that the enhancement of adhesion by Dex is associated with its effect of promoting cell viability to chemotherapy.

It is well known that adhesion molecular integrin $\beta 1$ subfamily plays a crucial role in regulating cell adhesion to ECM proteins, such as collagen, FN, and laminin (Hynes 1992, Rozzo et al. 1997, Jin \& Varner 2004). It has been reported that Dex shows cell typespecific regulation on the expression of integrin $\beta 1$. For example, the expressions of integrin $\beta 1 \mathrm{mRNA}$ and protein were reduced in human skin fibroblast (Zoppi et al. 1998) and human cytotrophoblast (Ryu et al. 1999), while they were induced in human gastric carcinoma cells (Murakami et al. 1998) by Dex. But there is no information about how Dex affects the expression of integrin $\beta 1$ in ovarian cancer cells. Our further experiment demonstrated that the expressions of integrin $\beta 1$ as well as of the two kinds of $\alpha$ subunits, $\alpha 4$ and $\alpha 5$, were up-regulated by Dex at the protein level in human ovarian cancer HO-8910 cells. And the regulation of Dex on integrin $\beta 1$ seems to occur at the post-transcriptional level since this regulation was not seen at the mRNA level (data not shown). Moreover, we demonstrated that the blocking of cell adhesion to ECM with neutralizing antibody of integrin $\beta 1$ significantly attenuated the protection of Dex from chemotherapy in HO-8910 cells, indicating that cell adhesion to ECM mediated by integrin $\beta 1$ adhesion molecule is responsible for the effect of Dex against chemotherapeutic agents. However, it should be pointed out that the neutralizing antibody of integrin $\beta 1$ could not completely block the Dex-induced cell adhesion to ECM, suggesting that other adhesion molecules besides integrin $\beta 1$ and/or other mechanisms may also be involved in the action of Dex. Our recent results indicate that Dex could enhance cell adhesion by increasing the expression of some ECM components, such as collagen I and hyaluronic acid, in HO-8910 cells (unpublished data). This finding is in line with the latest report that the enhanced ECM deposition may play a direct role in primary chemoresistance in ovarian carcinoma (Etemadmoghadam et al. 2009).

Several studies have reported that there is a synergistic effect between GC- and TGF- $\beta 1$-signaling pathways to regulate a variety of physiological and pathologic processes, such as modulating cell differentiation in osteoclast (Takuma et al. 2003) or cell growth in U937 cells (Kanatani et al. 1996). Since TGF- $\beta 1$ is the most important growth factor that facilitates cell adhesion to ECM by increasing matrix production and accumulation, and ovarian epithelial cells can secrete TGF- $\beta 1$ (Peng 2003), we therefore hypothesized that TGF- $\beta 1$-signaling pathway may be involved in Dex's role in pro-adhesion and prosurvival. The results of this experiment showed that TGF- $\beta 1$ alone has the pro-adhesion and pro-survival effects, although the effects are weaker than those of Dex, and the combination of Dex and TGF- $\beta 1$ showed the obvious synergistic effect on cell adhesion as well as on cell resistance to cisplatin. Furthermore, the neutralizing antibody of TGF- $\beta 1$ not only could significantly block the pro-adhesion and pro-survival effects of TGF- $\beta 1$ itself, but could also obviously inhibit the synergistic effect of Dex and TGF- $\beta 1$. These results suggested that there is a positive crosstalk between GC- and TGF- $\beta 1$-signaling pathways. Our previous studies found that Dex induced the expression of T $\beta R$-II and enhanced growth-inhibitory effect of TGF- $\beta 1$ on androgen-independent human prostate cancer PC-3 cells (Li et al. 2006). In this experiment, we also found that Dex up-regulated T $\beta R$-II expression, but did not affect the expression of TGF- $\beta 1$ and T $\beta$ R-I. We indeed demonstrated subsequently that Dex could enhance the responsiveness 
of HO-8910 cells to TGF- $\beta 1$ by a TGF- $\beta 1$-responsive reporter gene assay. Therefore, the induction of T $\beta R$-II expression by Dex may be an explanation for the Dex-enhanced TGF- $\beta 1$-induced cell adhesion to ECM and cell resistance to cisplatin in HO-8910 cells. Since we only observed the effect of Dex on TGF- $\beta 1$ signaling in this study, whether TGF- $\beta 1$ signaling can enhance the effect of Dex in turn is unclear now and it is worthy of further study.

In summary, using human cancer cell line, which is commonly used in the elucidation of the mechanisms responsible for the biological activity, we provide new evidence that Dex's role in pro-adhesion to ECM is one of the basic mechanisms of Dex-induced apoptotic resistance against chemotherapy. The pro-adhesion action of Dex is achieved at least by enhancing the protein levels of members of integrin $\beta 1$ subfamily and TGF- $\beta 1$-signaling pathway. It will be of considerable interest to know whether this effect of GC is involved in its cell protection against apoptosis induced by other harmful stimuli, such as hypoxia and ischemia. Furthermore, our studies are performed on human ovarian cancer cell line, and whether the conclusions could be applied to cancer cells from other epithelial origins is unknown. Additional experiments will be required to extend our conclusions.

\section{Declaration of interest}

The authors declare that there is no conflict of interest that could be perceived as prejudicing the impartiality of this research.

\section{Funding}

This work was supported by a grant from the National Natural Science Foundation of China (No. 30470671).

\section{Acknowledgements}

We thank Dr Joan Massague for kindly providing us with the p3TP-Luc construct and Dr Yi-Li Yang for critical read.

\section{References}

Bailly-Maitre B, de Sousa G, Zucchini N, Gugenheim J, Boulukos KE \& Rahmani R 2002 Spontaneous apoptosis in primary cultures of human and rat hepatocytes: molecular mechanisms and regulation by dexamethasone. Cell Death and Differentiation 9 945-955.

Brenner RE, Felger D, Winter C, Christiansen A, Hofmann D \& Bartmann P 2001 Effects of dexamethasone on proliferation, chemotaxis, collagen I, and fibronectinmetabolism of human fetal lung fibroblasts. Pediatric Pulmonology 32 1-7.
Chen BQ, Yang YM, Wang Q, Gao YH, Liu JR, Zhang JS, Wang XL \& Liu RH 2004 Effects of c9,t11-conjugated linoleic acid on adhesion of human gastric carcinoma cell line SGC-7901. World Journal of Gastroenterology 10 1392-1396.

Chen YX, Li ZB, Diao F, Cao DM, Fu CC \& Lu J 2006 Up-regulation of RhoB by glucocorticoids and its effects on the cell proliferation and NF-kappaB transcriptional activity. Journal of Steroid Biochemistry and Molecular Biology 101 179-187.

Dawes LJ, Elliott RM, Reddan JR, Wormstone YM \& Wormstone IM 2007 Oligonucleotide microarray analysis of human lens epithelial cells: TGFbeta regulated gene expression. Molecular Vision 13 1181-1197.

Etemadmoghadam D, deFazio A, Beroukhim R, Mermel C, George J, Getz G, Tothill R, Okamoto A, Raeder MB, Harnett $\mathrm{P}$ et al. 2009 Integrated genome-wide DNA copy number and expression analysis identifies distinct mechanisms of primary chemoresistance in ovarian carcinomas. Clinical Cancer Research 15 1417-1427.

Frei E III, Karon M, Levin RH, Freireich EJ, Taylor RJ, Hananian J, Selawry O, Holland JF, Hoogstraten B, Wolman IJ et al. 1965 The effectiveness of combinations of antileukemic agents in inducing and maintaining remission in children with acute leukemia. Blood 26 642-656.

Gassler N, Zhang C, Wenger T, Schnabel PA, Dienemann H, Debatin KM, Mattern J \& Herr I 2005 Dexamethasoneinduced cisplatin and gemcitabine resistance in lung carcinoma samples treated ex vivo. British Journal of Cancer 92 1084-1088.

Guller S, Kong L, Wozniak R \& Lockwood CJ 1995 a Reduction of extracellular matrix protein expression in human amnion epithelial cells by glucocorticoids: a potential role in preterm rupture of the fetal membranes. Journal of Clinical Endocrinology and Metabolism 80 2244-2250.

Guller S, Wozniak R, Kong L \& Lockwood CJ $1995 b$ Opposing actions of transforming growth factor-beta and glucocorticoids in the regulation of fibronectin expression in the human placenta. Journal of Clinical Endocrinology and Metabolism 80 3273-3278.

Herr I, Ucur E, Herzer K, Okouoyo S, Ridder R, Krammer PH, von Knebel Doeberitz M \& Debatin KM 2003 Glucocorticoid cotreatment induces apoptosis resistance toward cancer therapy in carcinomas. Cancer Research 63 3112-3120.

Herr I, Gassler N, Friess H \& Buchler MW 2007 Regulation of differential pro- and anti-apoptotic signaling by glucocorticoids. Apoptosis 12 271-291.

Hynes RO 1992 Integrins: versatility, modulation, and signaling in cell adhesion. Cell 69 11-25.

Jin H \& Varner J 2004 Integrins: roles in cancer development and as treatment targets. British Journal of Cancer $\mathbf{9 0}$ $561-565$. 
Kanatani Y, Kasukabe T, Okabe-Kado J, Hayashi S, Yamamoto-Yamaguchi Y, Motoyoshi K, Nagata N \& Honma Y 1996 Transforming growth factor beta and dexamethasone cooperatively enhance c-jun gene expression and inhibit the growth of human monocytoid leukemia cells. Cell Growth and Differentiation 7 187-196.

Kappert K, Schmidt G, Doerr G, Wollert-Wulf B, Fleck E \& Graf K 2000 Angiotensin II and PDGF-BB stimulate beta(1)-integrin-mediated adhesion and spreading in human VSMCs. Hypertension 35 255-261.

Kriegler AB, Bernardo D \& Verschoor SM 1994 Protection of murine bone marrow by dexamethasone during cytotoxic chemotherapy. Blood 83 65-71.

Li Z, Chen Y, Cao D, Wang Y, Chen G, Zhang S \& Lu J 2006 Glucocorticoid up-regulates transforming growth factor-beta (TGF-beta) type II receptor and enhances TGF-beta signaling in human prostate cancer PC-3 cells. Endocrinology 147 5259-5267.

Mattern J, Buchler MW \& Herr I 2007 Cell cycle arrest by glucocorticoids may protect normal tissue and solid tumors from cancer therapy. Cancer Biology \& Therapy 6 1345-1354.

Mikosz CA, Brickley DR, Sharkey MS, Moran TW \& Conzen SD 2001 Glucocorticoid receptor-mediated protection from apoptosis is associated with induction of the serine/threonine survival kinase gene, sgk-1. Journal of Biological Chemistry 276 16649-16654.

Moran TJ, Gray S, Mikosz CA \& Conzen SD 2000 The glucocorticoid receptor mediates a survival signal in human mammary epithelial cells. Cancer Research $\mathbf{6 0}$ 867-872.

Murakami N, Fukuchi S, Takeuchi K, Hori T, Shibamoto S \& Ito F 1998 Antagonistic regulation of cell migration by epidermal growth factor and glucocorticoid in human gastric carcinoma cells. Journal of Cellular Physiology 176 127-137.

Peng C 2003 The TGF-beta superfamily and its roles in the human ovary and placenta. Journal of Obstetrics and Gynaecology Canada 25 834-844.

Pinkse GG, Voorhoeve MP, Noteborn M, Terpstra OT, Bruijn JA \& De Heer E 2004 Hepatocyte survival depends on beta1-integrin-mediated attachment of hepatocytes to hepatic extracellular matrix. Liver International $\mathbf{2 4}$ 218-226.

Rozzo C, Chiesa V, Caridi G, Pagnan G \& Ponzoni M 1997 Induction of apoptosis in human neuroblastoma cells by abrogation of integrin-mediated cell adhesion. International Journal of Cancer 70 688-698.

Runnebaum IB \& Brüning A 2005 Glucocorticoids inhibits cell death in ovarian cancer and up-regulate caspase inhibitor cIAP2. Clinical Cancer Research 11 6325-6332.

Rutz HP 2002 Effects of corticosteroid use on treatment of solid tumours. Lancet 360 1969-1970.

Rutz HP \& Herr I 2004 Interference of glucocorticoids with apoptosis signaling and host-tumor interactions. Cancer Biology and Therapy 3 715-718.
Ryu JS, Majeska RJ, Ma Y, LaChapelle L \& Guller S 1999 Steroid regulation of human placental integrins: suppression of alpha2 integrin expression in cytotrophoblasts by glucocorticoids. Endocrinology 140 3904-3908.

Sawhney RS 2002 Expression and regulation of SPARC, fibronectin, and collagen IV by dexamethasone in lens epithelial cells. Cell Biology International 26 971-983.

Schmidt S, Rainer J, Ploner C, Presul E, Riml S \& Kofler R 2004 Glucocorticoid-induced apoptosis and glucocorticoid resistance: molecular mechanisms and clinical relevance. Cell Death and Differentiation 11 S45-S55.

Schorr K \& Furth PA 2000 Induction of bcl-xL expression in mammary epithelial cells is glucocorticoid-dependent but not signal transducer and activator of transcription 5-dependent. Cancer Research 60 5950-5953.

Sui M, Chen F, Chen Z \& Fan W 2006 Glucocorticoids interfere with therapeutic efficacy of paclitaxel against human breast and ovarian xenograft tumors. International Journal of Cancer 119 712-717.

Takuma A, Kaneda T, Sato T, Ninomiya S, Kumegawa M \& Hakeda Y 2003 Dexamethasone enhances osteoclast formation synergistically with transforming growth factor-beta by stimulating the priming of osteoclast progenitors for differentiation into osteoclasts. Journal of Biological Chemistry 278 44667-44674.

Webster JC, Huber RM, Hanson RL, Collier PM, Haws TF, Mills JK, Burn TC \& Allegretto EA 2002 Dexamethasone and tumor necrosis factor-alpha act together to induce the cellular inhibitor of apoptosis-2 gene and prevent apoptosis in a variety of cell types. Endocrinology 143 3866-3874.

Weller M, Schmidt C, Roth W \& Dichgans J 1997 Chemotherapy of human malignant glioma: prevention of efficacy by dexamethasone? Neurology 48 1704-1709.

Wolff JE, Denecke J \& Jürgens H 1996 Dexamethasone induces partial resistance to cisplatinum in C6 glioma cells. Anticancer Research 16 805-809.

Wu W, Chaudhuri S, Brickley DR, Pang D, Karrison T \& Conzen SD 2004 Microarray analysis reveals glucocorticoid-regulated survival genes that are associated with inhibition of apoptosis in breast epithelial cells. Cancer Research 64 1757-1764.

Wu W, Pew T, Zou M, Pang D \& Conzen SD 2005 Glucocorticoid receptor-induced MAPK phosphatase-1 (MPK-1) expression inhibits paclitaxel-associated MAPK activation and contributes to breast cancer cell survival. Journal of Biological Chemistry 280 4117-4124.

Zhang HH, Kumar S, Barnett AH \& Eggo MC 2001 Dexamethasone inhibits tumor necrosis factor-alphainduced apoptosis and interleukin-1 beta release in human subcutaneous adipocytes and preadipocytes. Journal of Clinical Endocrinology and Metabolism 86 2817-2825. 
Zhang C, Beckermann B, Kallifatidis G, Liu Z, Rittgen W, Edler L, Buchler P, Debatin KM, Buchler MW, Friess H et al. 2006 a Corticosteroids induce chemotherapy resistance in the majority of tumour cells from bone, brain, breast, cervix, melanoma and neuroblastoma. International Journal of Oncology 29 1295-1301.

Zhang C, Kolb A, Buchler P, Cato AC, Mattern J, Rittgen W, Edler L, Debatin KM, Buchler MW, Friess H et al. $2006 b$ Corticosteroid co-treatment induces resistance to chemotherapy in surgical resections, xenografts and established cell lines of pancreatic cancer. BMC Cancer 661.

Zhang C, Kolb A, Mattern J, Gassler N, Wenger T, Herzer K, Debatin KM, Buchler M, Friess H, Rittgen W et al. 2006c Dexamethasone desensitizes hepatocellular and colorectal tumours toward cytotoxic therapy. Cancer Letters $\mathbf{2 4 2}$ 104-111.

Zhang C, Marme A, Wenger T, Gutwein P, Edler L, Rittgen W, Debatin KM, Altevogt P, Mattern J \& Herr I 2006d
Glucocorticoid-mediated inhibition of chemotherapy in ovarian carcinomas. International Journal of Oncology 28 551-558.

Zhang C, Mattern J, Haferkamp A, Pfitzenmaier J, Hohenfellner M, Rittgen W, Edler L, Debatin KM, Groene E \& Herr I 2006e Corticosteroid-induced chemotherapy resistance in urological cancers. Cancer Biology and Therapy 5 59-64.

Zhang C, Wenger T, Mattern J, Ilea S, Frey C, Gutwein P, Altevogt P, Bodenmüller W, Gassler N, Schnabel PA et al. 2007 Clinical and mechanistic aspects of glucocorticoidinduced chemotherapy resistance in the majority of solid tumors. Cancer Biology and Therapy 6 278-287.

Zoppi N, Ghinelli A, Gardella R, Barlati S \& Colombi M 1998 Effect of dexamethasone on the assembly of the matrix of fibronectin and on its receptors organization in Ehlers-Danlos syndrome skin fibroblasts. Cell Biology International 22 499-508. 